fato foi realizado e a argumentação que acusava descaso, a autora chama atenção para uma certa contradição, que pode ser percebida no próprio álbum de recortes mantido no arquivo de Oswaldo Cruz. Segundo a autora, "a impressão que se tem é de que Oswaldo Cruz teria recebido as homenagens que lhe eram devidas", e apesar disso, o discurso mantido por seus amigos apela para a consciência social e coletiva, para o que representa a sua morte, para a necessidade de dar continuidade ao projeto e à obra em respeito àquele homem. Como diria Neiva em relação à responsabilidade de continuar a obra “...A sua luminosa memória não nos deixará desanimar em meio a tantas tormentas...". Assim a autora prepara o leitor para refletir sobre o projeto de continuar sob a sombra de um ideal, ou de um mito.

No capítulo seguinte, Nara Britto repassa os discursos de seguidores e discípulos em seu desafio de continuar sem a presença física de Oswaldo, seus sentimentos expressos em documentos ou livros são apresentados. Os problemas apontados não seriam de ordem prática, dado que Carlos Chagas já havia sido nomeado para o cargo de Diretor do Instituto, tornando de direito uma situação que já exercia de fato. Respeitado e reconhecido por sua mais importante obra, era um homem de porte científico e médico inquestionável. O Instituto, no entanto, não era um bloco único, havendo dissidências e confrontos internos com os quais já vinha lidando ao longo dos anos Oswaldo em sua condução do projeto. Com a morte dele, os riscos representados pelos desafetos e conflitos contidos sob uma liderança inquestionável eram evidentes. Disputava-se o mérito científico, ambicionava-se o cargo de Oswaldo Cruz. Difícil não segmentar por diferentes critérios uma equipe dotada de múltiplos talentos e perfis profissionais tão diferenciados, difícil não politizar as disputar pelo poder e pela sucessão. Disso nos fala a autora com base em documentos e testemunhos de Rocha Lima, Arthur Neiva, Lobato Paraense e outros. Mexendo em tema-tabu, Nara fala das fraturas, dos desequilíbrios, das fragilidades sob o manto de Manguinhos, do concurso, do oportunismo político, das manobras. Segundo a autora, na morte de Oswaldo o Instituto de Manguinhos estava num momento de extrema fragilidade, com relações internas deterioradas, e a perda do mentor contribui para o perigoso aprofundamento de fissuras institucionais. Como propõe, "Este foi o dilema vivido pelos pesquisadores do Instituto após o desaparecimento de Oswaldo Cruz. A questão que se colocava para este grupo era a de garantir o reconhecimento de sua própria competência intelectual beneficiar-se do prestígio de que Oswaldo Cruz, e por extensão, Manguinhos, haviam gozado desde então".

No penúltimo capítulo, Nara apresenta o culto à memória de Oswaldo Cruz e o contrasta com os testemunhos de seu cotidiano, de sua vida real. Argumenta que esse culto, mantido no círculo de discípulos e amigos, em princípio espontâneo e fruto das emoções da perda, teria evoluído para uma intencionalidade, no sentido de contribuir para a construção de uma imagem perfeita do cientista e do homem, um símbolo da ciência brasileira. Com a Liga Pró-Saneamento como um dos mais importantes veículos de difusão dessas idéias, mantinha-se o lema "Não esmorecer, para não desmerecer”. Discutindo o grande número de metáforas empregadas pelos seus biógrafos e enaltecedores, a autora reflete sobre a existência no decorrer deste processo de uma quase religiosidade, a atribuição de um caráter missioneiro, e quase místico a Oswaldo. Ainda segundo a autora, um eficiente elemento para a constituição da identidade sanitarista. Ressalta os textos publicados pelos discípulos, entre 1917 e 1922, sobre o mestre, e contrasta a imagem construída com o comportamento cotidiano do homem em seu trabalho. Também discute a figura peculiar do homem Oswaldo e seus atributos. Como físico e postura chamava atenção, contrastava, destoava. O que teria Oswaldo que o tornou tão especial, diferente e competente? Apresenta a opinião contrastante de alguns memorialistas, discute Clementino Fraga em sua crítica à imagem de Oswaldo como predestinado. Mostra quanto os memorialistas pouparam sua história dos momentos mais polêmicos e criticados. Revendo os que contaram sua vida, a autora discute a imagem de Oswaldo como o saneador do Rio de Janeiro e o fundador da medicina experimental, mais um herói nacional elevado ao panteão cívico do Brasil.

Nos comentários finais, Nara conclui sua idéia central: de que a morte de Oswaldo Cruz propicia sua heroificação, redimindo pecados, encerrando polêmicas, fazendo-o transcender. Se por um lado mostra que para a construção do mito do herói atuaram decisivamente seus seguidores e discípulos, por outro admite que muitos atores de fora teriam contribuído com este processo. Propõe que o mito de Oswaldo Cruz é um " $f e$ nômeno ideológico de natureza cientificista", que traduz anseios de um grupo num dado momento histórico do país.

Ao encerrar seu trabalho, lembra que de um modo ou de outro, e quaisquer que tenham sido as conseqüências dessa mitificação, a figura de Oswaldo Cruz destaca-se hoje entre os heróis nacionais como um representante ainda solitário da ciência brasileira.

O livro traz fatos e demonstra como se constroem as histórias e ideais, os mitos e os poderes de homens e de instituições. No livro de Nara aprendemos mais uma vez sobre nossa própria história e nossas fundações, sobre o jogo dos valores e sua importância, sobre a impossibilidade de ter uma ciência isolada da sociedade, das conjunturas políticas, sobre a política que perpassa as instituições científicas, sobre os animais políticos que constroem as instituições científicas. Um livro para ser lido principalmente pelos que ainda pensam que seus laboratórios, gabinetes ou outras salas de trabalho são domínios estanques de saber e de poder.

Sheila Maria Ferraz Mendonça de Souza

Escola Nacional de Saúde Pública Sergio Arouca, Fundação

Oswaldo Cruz, Rio de Janeiro, Brasil.

sferraz@ensp.fiocruz.br

\section{A CONSTRUÇÃO DA CLÍNICA AMPLIADA NA} ATENÇÃO BÁSICA. Cunha GT. São Paulo: Editora Hucitec; 2005. 212 pp.

ISBN: 85-27106-75-2

No marco das políticas de humanização da atenção à saúde (HumanizaSUS: Política Nacional Humanização; http://www.saúde.gov.br/humanizasus), o investimento nas tecnologias do cuidado humanizado contrasta ainda com uma cultura técnica carente de revisão acerca dos marcos do poder, da verticalização das relações e da promoção de um ambiente mais afeito à criatividade e ao afeto. É nesse marco histórico e político que o livro de Gustavo Cunha reúne seu pensamento em 
torno da tarefa de discutir a prática clínica na atenção básica, acentuando que esta clínica, qualificada como ampliada, enfrenta o desafio de encarar com seriedade os sujeitos: o cuidador/profissional e o que é cuidado.

Um dos esforços da Política Nacional de Humanização (PNH) está na possibilidade de retomar o papel central do sujeito enfermo dentro das práticas terapêuticas do sistema de saúde, e dos trabalhadores como protagonistas que têm como responsabilidade operar no sistema, mediando relações e construindo práticas que estimulem a participação. O termo humanização no interior da $\mathrm{PNH}$ engloba as seguintes perspectivas: (i) valorização dos diferentes sujeitos implicados no processo de produção de saúde: usuários, trabalhadores e gestores; (ii) fomento da autonomia e do protagonismo destes sujeitos; (iii) aumento do grau de co-responsabilidade na produção de saúde e de sujeitos.

No interior desse cenário construímos a resenha do livro de Gustavo Tenório Cunha apontando para o fato de que a formulação de uma clínica ampliada opera com os dois nichos cruciais da PNH: o eixo do sujeito enfermo e o eixo do processo de trabalho do profissional que dedica-se ao cuidado da saúde humana. Logo na apresentação o autor sintetiza essa tarefa que reencontra os sujeitos, o que cuida e o que é cuidado. $\mathrm{Na}$ dimensão desse encontro entre usuário e trabalhador de saúde no contexto da atenção básica reside um dilema entre complexidade do trabalho e simplificação da tarefa. Ao nosso ver, se é ao contexto da atenção básica que o autor se reporta - muito embora o conceito de clínica ampliada remonte de uma forma mais geral ao território da saúde, tal como referido por Campos 1 - esse dilema não se resume a esse contexto. A área da saúde envolve um campo complexo de relações no qual se situam diversos atores, com projetos que podem paradoxalmente revelar-se contraditórios e complementares. Nesse paradoxo uma das possibilidades de trabalho reside no reconhecimento de que o conflito entre posições é também motor da história, logo nele reside a possibilidade da construção de pactos, negociações e diálogos.

As idéias do autor estão organizadas em seu livro em quatro capítulos, que seguem uma lógica que no Capítulo 1 permite a aproximação gradual com o campo da atenção básica, suas características, os limites que enfrentam essa atenção pela perspectiva da ação hospitalar, e a defesa de uma ampliação da clínica. O Capítulo 2 está basicamente centrado no esforço de resgatar um modelo possível para uma análise que inova a clínica não mais pensada a partir de um a priori individual, mas na perspectiva da dialética entre sujeitos/perspectiva singular/coletividade, com referências a Gastão Wagner de Souza Campos e ao Método da Roda, e ainda a Análise Institucional e a Esquizoanálise. Nesse capítulo o leitor é apresentado a exemplos ilustrativos do chamamento provocado pelos usuários do sistema de saúde a uma ampliação do olhar técnico, e a uma ampliação da escuta e das formas de trabalhar com as demandas. Os padrões hegemônicos de tratamento e de diagnóstico são criticados com exemplos que partem de uma experiência na Califórnia, Estados Unidos, e chegam ao Brasil. Nesse capítulo o autor nos presenteia com uma escrita repleta de exemplos, e pari passu a esta ele vai tecendo a teia das discussões e análises teóricas. Após essas considerações, críticas e avaliação de limites, no Capítulo 3 o autor prepara o campo para uma exposição mais detalhada sobre o conceito de clínica ampliada e sobre seus "filtros teóricos", sempre contribuindo com exemplos da ordem da vida. É interessante observar que ao buscar as aproximações entre as correntes teóricas que contribuem para a construção do conceito de clínica ampliada, o autor torna possível também diferenciar o Método da Roda - base estratégica de enfrentamento e ação na clínica e na gestão ampliada - dos métodos psicanalítico e esquizoanalítico. Nesse ponto, não interessam nem as ações que intervêm muito pouco, respeitando uma suposta "liberdade associativa", nem muito menos a idéia de que existe uma "produção de subjetividade" como único paradigma acerca dos sujeitos. O autor destaca que na Clínica Ampliada na Atenção Básica as intervenções no plano biológico se combinam aos impactos subjetivos, disparando produções e abrindo caminhos terapêuticos para o sujeito doente.

O autor evoca sua experiência no contexto da atenção básica, enquanto médico generalista, e mais do que simplesmente descrever esta experiência ele aprofunda o impacto de suas observações e as transforma em material crítico, material de análise, motor de trabalho. Suas ferramentas analíticas contam com autores de importância crucial no campo da saúde coletiva, e não se furta a acessar as perspectivas da sociologia, psicanálise, análise institucional e das chamadas práticas integrativas (homeopatia e medicina tradicional chinesa) como caminhos para a construção de uma clínica ampliada pelo lado da produção de subjetividade. Do lado da gestão em saúde - que também é um espaço onde são produzidos sujeitos, organizadas práticas - nos parece interessante assinalar a operação, pelo autor, com categorias analíticas que dizem respeito ao cotidiano do planejamento e da produção institucional e também estão presentes no processo de produção da clínica, quais sejam: poder, sujeito, saber, imaginário social e iatrogenias.

No Capítulo 4, dialogando com as ferramentas da gestão, dentre elas os chamados protocolos ou guidelines, o autor promove uma análise importante acerca de seus limites e do quanto eles podem promover uma alienação no trabalho, quando passam a ser usados indiscriminadamente como padrões, onde se perde a perspectiva originária de sua formulação. Os limites dos guidelines e protocolos para as situações complexas e a abordagem de doenças crônicas, é um dos pontos referidos pelo autor. As situações de emergência e urgência ou as doenças muito graves são locus onde esses protocolos apresentam um sentido muito maior. É assim que centralidade dos aspectos biológicos e a perspectiva de imutabilidade dos sujeitos invadiu a clínica tradicional, e fez da Programação em Saúde um espaço de relações onde predominam as agendas fixas de acordo com o perfil dos pacientes a serem tratados. Esses parecem que não evoluem em seus quadros, e reificam-se na perspectiva diagnóstica, e têm seus retornos sempre agendados fixamente, oferecendo-se um cardápio de recursos invariáveis às necessidades possivelmente muito variáveis e permeadas de componentes de imprevisibilidade - de atenção. $\mathrm{O}$ autor defende a idéia de que o espaço da saúde é um território aberto à produção e à variação, portanto, faz-se necessário que as equipes promovam avaliações constantes no seu cardápio de recursos e respectivos impactos. O autor aponta ainda para os limites da Medicina Baseada em Evidências, que ao apoiar suas evidências em populações altamente selecionadas e não representati- 
vas, além de que suas ferramentas epidemiológicas não são sensíveis aos conflitos de interesses, e as variações no campo das relações entre profissional e paciente acabam por não conseguir responder à singularidade de cada situação apresentada na atenção básica. Segundo o autor, a utilização acrítica dessas ferramentas (Programação em Saúde, Guidelines e Medicina Baseada em Evidências) pode tornar-se um obstáculo a mais para a ampliação da clínica e para a construção de um diálogo que desconstrua a pretensão totalizante e generalizante da ação em saúde.

Finalizando, acreditamos que alguns recursos apontados pelo autor como essenciais para as equipes que agem com antiprotocolos, deveriam estar no cerne de uma construção ampliada de saúde, e que contribuiria para ações interdisciplinares, quais sejam: (i) as reuniões de equipe, que associem a fraternidade da troca à necessária objetividade dos projetos e discussões; (ii) o projeto terapêutico singular, que supera o individual do caso clínico para pensar na rede social e familiar que conforma o sujeito doente; (iii) uma anamnese ampliada; (iv) a visita domiciliar como um recurso importante de acesso à dinâmica familiar. Os pontos anteriores, olhados cuidadosamente, fazemnos pensar que o trabalho em saúde, suas dificuldades e impasses não significam derrotas absolutas, mas nos ensinam a superar estes sentimentos e construir uma prática na qual a incompletude aponta para a necessidade de trabalhar com a alteridade e a horizontalidade das relações em direção a um projeto interdisciplinar e humano.

Martha Cristina Nunes Moreira

Instituto Fernandes Figueira, Fundação Oswaldo Cruz, Rio de Janeiro, Brasil.

moreira@iff.fiocruz.br

1. Campos GWS. Saúde paidéia. São Paulo: Editora Hucitec; 2003.

A CIÊNCIA COMO PROFISSÃO: MÉDICOS, BACHARÉIS E CIENTISTAS NO BRASIL (18951935). Sá DM. Rio de Janeiro: Editora Fiocruz; 2006. 216 pp. (Coleção História e Saúde). ISBN: 85-7541-077-6

O livro A Ciência como Profissão: Médicos, Bacharéis e Cientistas no Brasil (1895-1935) tem uma primeira qualidade, que se desdobra em várias outras: uma escrita clara e bem elaborada, capaz de desenhar uma problemática atraente e agradável, característica não muito comum aos trabalhos científicos, como bem mostra a autora. Junte-se a isso o fato de que este livro traz à baila uma temática importante no processo de constituição da modernidade no Brasil: as bases da formação de uma comunidade científica orientada por parâmetros que se estabeleciam como dominantes nos países mais avançados.

Mas como se conta essa história? Qual é exatamente a história a ser contada? Começando pela primeira pergunta, o como, encontra-se, no primeiro capítulo, uma rica discussão da historiografia da ciência e, subordinada a ela, de uma forma um tanto truncada, da sociologia da ciência, ou, pelo menos, de uma versão dela que a autora por vezes chama de "análise institucional". A perspectiva apresentada tem o mérito, inegável, de chamar a atenção para alguns equívocos his- tóricos resultantes de abordagens tão marcadamente paulistas que acabam deixando de lado fatos relevantes, como a criação da primeira universidade no Brasil, em 1920, no Rio de Janeiro. Entretanto, a insistência em "inverter a tradicional causalidade sociológica contexto/produção de textos", em vez de levar a uma "reflexão pluricausal”, cria dificuldades para realizar a proposição ampla: "compreender como os cientistas brasileiros das primeiras décadas do século XX, ao informar os traços e perfis que reconheciam então em si mesmos, estavam escrevendo contra os padrões estabelecidos, idealizando na verdade uma nova identidade e um novo sentido para seu mundo". A apresentação dos discursos é extremamente bem feita, mas alguns leitores podem ficar desapontados pela ausência de uma descrição mais trabalhada dos "traços e perfis" objetivos desses atores.

Quanto à segunda questão: qual é a história contada? Na verdade, tem-se aqui uma "história da corte brasileira” em período de mudança política e social (a virada do século XIX ao XX), vista particularmente pelo ângulo das percepções distintas do que seria o verdadeiro trabalho científico, da transformação do sentido que se atribuía à cultura e da representação que se fazia, em nosso país, do que deveria ser o "homem culto". As facetas distintas desse "homem culto" são evidenciadas nos embates entre os antiquados bacharéis com sua vocação literária, pomposa e retórica, e os novos cientistas, distantes da linguagem do "belo" para tentar chegar ao "racional". Assim, assistimos a disputas (verbais, ou no máximo, por cargos...) algumas vezes ferozes, nas quais, aparentemente, mais que desenvolver aquilo que já foi chamado de "saberes modernos", tratava-se de denegrir as formas antigas do pensamento “enciclopédico", considerado então um empecilho ao progresso que a ciência prometia.

No segundo capítulo, a autora mostra que aquilo que outrora se constituíra em motivo de orgulho, nossa glória intelectual, nossos autores e oradores donos de amplos (mesmo que pouco profundos) conhecimentos sobre o mundo, passam a ser objeto de chacota, de crítica desdenhosa por parte da "sociedade culta da capital federal". Os intelectuais (uma lista imensa de possibilidades: “doutores, cronistas, bacharéis, parlamentares, poetas, publicistas, declamadores, médicos, letristas, escritores, conferencistas, acadêmicos, filólogos, romancistas, artistas, oradores, polemistas, professores, prosadores, polígrafos, sábios ou homens de ciências, conhecedores de várias línguas, líricos") eram pessoas bem nascidas, formalmente educadas e passíveis de classificação tanto como "homens de letras" ("enciclopédicos e poliglotas, seu delicado espírito fora educado pela literatura") quanto como "homens de ciências" ("porque por elas ilustrados").

No quadro da sociedade do século XIX, dominava uma cultura "auditiva" na qual a difusão do conhecimento se fazia fundamentalmente de forma oral, por meio de conferências, tribunas parlamentares, lições, memórias. Perfeitamente adaptados a ela, nossos intelectuais de outrora expressavam também uma representação tradicional do mundo onde o título de doutor transfigurava-se numa série de privilégios sociais. E, nesse ponto, surge uma indagação que perpassa todo o livro, ainda que não se explicite como tal: quais seriam os elementos propriamente sociais que poderiam distinguir aqueles que eram chamados de intelectuais ou literatos daqueles que ficaram conhecidos como cientistas? Pela forma da narrativa, fica difícil distin- 